\title{
To Explore the Impact of Medical Education on Sleep Quality toward Quality of Life
}

\author{
Yuzhou Luo ${ }^{1 *}$, Zhaoyan Hu ${ }^{1}$, Fang $\mathrm{Xu}^{2}$ \\ ${ }^{1}$ School of Medical Instruments, Shanghai University of Medicine \& Health Sciences, Shanghai, CHINA \\ 2 Planning Development Branch, University of Shanghai for Science and Technology, Shanghai, CHINA
}

Received 30 December 2017 - Revised 6 April 2018 • Accepted 1 May 2018

\begin{abstract}
Sleep is the basic physiological needs of human beings, while sleep disorder commonly occur in the public. Bad sleep quality would result in bad work efficiency and low quality of life. Insomnia problem is regarded as a disease seriously affecting quality of life in current industrial and commercial societies. Medical education allows students presenting further cognition of self-health concepts and people understanding that proper physical activity could enhance citizens' physical fitness, reduce the occurrence of chronic diseases, and largely help the expenditure of social medical expenses. Apparently, medical education is primary for human health. With experimental design, total 200 students in four classes of the University in Shanghai, as the research object, are proceeded 16-week ( $3 \mathrm{hrs}$ per week for total 48 hours) experimental teaching. The research results reveal the significant correlation between 1.medical education and sleep quality, 2.sleep quality and quality of life, and 3.medical education and quality of life. According to the results and findings, practical suggestions are proposed in this study, expecting to reinforce relevant medical education and draft lifestyles to enhance the sleep quality and quality of life.
\end{abstract}

Keywords: medical education, sleep quality, quality of life, health

\section{INTRODUCTION}

Along with the advance of time, technological and user-friendly products have modern people's life seriously approaching automation and networking. About 60-85\% global population therefore show sedentary lifestyle and short physical activity to enhance physical function degradation and mental weakness as well as low quality of life and life meaning. Such a situation has been globally concerned in human health. Sleep is the fundamental physiological need for human beings, as eating, breathing, and drinking water to maintain people's normal life and health status. According to the survey of World Health Organization in 2004, Li et al. (2017) pointed out the factors in sleep, including participation in exercise, environment, work stress, diet habit, drug use, disease, and physical composition. Bad sleep quality would result in bad work efficiency and low quality of life, and long-term shortage of sleep would appear the symptoms of burnout, drowsiness, irritability, memory decline, exhaustion, lack of motivation for work, impaired concentration, and easy conflict with people. Bad sleep quality might result in students' bad performance on schoolwork and exercise, influence emotion, and even cause psychological problems of melancholy. Sleep disorder is a common health problem of the public, in which insomnia problem is regarded as a serious disease to seriously influence quality of life in modern industrial and commercial societies.

Health is the basic need for human beings as well as the primary condition for high quality of life. The establishment of medical education in schools is considered as the fundamental method to enhance national health, as medical teaching allows people understanding the importance of health and factors in diseases to further cultivate the responsible attitudes for personal health and establish correct health behaviors and lifestyles. Medical education could have students show further cognition of self-health and people understand that proper physical activity could enhance citizens' physical fitness, reduce the occurrence of chronic diseases, and largely assist in the expenditure of social medical expenses. Psychologically, medical education could improve individual emotion,

(C) 2018 by the authors; licensee Modestum Ltd., UK. This article is an open access article distributed under the terms and conditions of the Creative Commons Attribution License (http://creativecommons.org/licenses/by/4.0/).

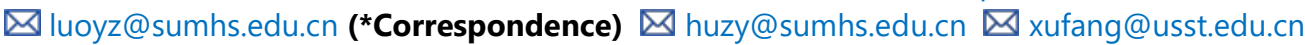




\section{Contribution of this paper to the literature}

- The course and philosophy of medical education in teacher training schools are reinforced so that students pay attention to the cultivation of healthy living habits in the beginning of the school education, understanding the importance and function of medical education, and even being capable of applying it to the health behaviors in adult.

- Schools are suggested to encourage students participating in exercise through health promotion activity to cultivate regular exercise habits, enhance the atmosphere of students participating in exercise, and cultivate the habit of regular exercise so as to enhance personal health and create good sleep quality and quality of life.

- Medical education could be practiced with multi-culture and computer-assisted teaching is preceded through the Internet so that students could acquire health knowledge and resources from the network to achieve the self-learning ability and be responsible for self-health.

stress, self-esteem, physical image, and self-concept. The importance of medical education to physical health is apparent. This study therefore intends to investigate the effect of medical education on sleep quality and quality of life, expecting to draft lifestyles, by reinforcing relevant medical education, to enhance the sleep quality and quality of life.

\section{LITERATURE REVIEW}

\section{Medical Education}

Zou et al. (2017) regarded medical education as the process people enriching health knowledge and establishing and cultivating habits as well as a life course. Barons et al. (2015) defined medical education as the education or training which could help enhance or develop medical professional knowledge, inference and explanation capability as well as appropriate professional skills to achieve sound doctor-patient relationship standard or ability. Kayaba et al. (2014) revealed that medical education aimed to explain the social activity of the system in which group of people or individuals improved health related behaviors, and, based on the survey, the intervening measure of health information spread was applied to group of people or individuals self-consciously adopting behaviors and lifestyles beneficial to health so as to avoid or reduce the exposure in dangerous factors, help the implementation of disease prevention, treatment, and recovery, and enhance the level of health. Cakici et al. (2015) referred medical education as having people self-consciously adopt behaviors and lifestyles beneficial to health through planned, organizational, and systematic social education activity to eliminate or reduce dangerous factors in health, prevent diseases, enhance health, promote quality of life, and evaluate education effects. Liang et al. (2016) mentioned that the core of medical education was to educate people building health awareness, enhance people to change unhealthy behaviors and lifestyles, and cultivate good behaviors and lifestyles to reduce or eliminate dangerous factors in health. Chiu et al. (2015) indicated that medical education could help people understand health-affected behaviors and self-consciously choose behaviors and lifestyles beneficial to health.

Referring to Lin (2016), two dimensions of health promotion and related behavior are covered in medical education in this study.

(1) Health promotion: Referring to the complex to have behaviors and life conditions approach education and environment support for changing health.

(2) Related behavior: Referring to individual or group behaviors related to health and diseases.

\section{Sleep Quality}

Sleep is a normal physiological behavior and the process humans being unconscious of external environment but could awake and recover by environmental stimuli (Lajnef et al., 2015; de Arriba Pérez et al., 2016; Wysocki, Balcerzak, Prus, Niemczyk, Lachowska, 2016; Moon, Kong, Oh, Kim, 2018). Being a primary physiological function to maintain human life, sleep is the fundamental element of life like eating, breathing, and drinking water. Bernert et al. (2014) indicated that sleep was the rest state when the simulation information of brain reticular formation and cerebral cortex appeared less frequent transmission. At the time, people showed less feeling and consciousness of external environment and low alertness and did not easily present instant responses to environmental changes and stimuli. Sleep quality was a complicated physiological health issue, which involved in broad factors, including individual physiological health, genetic factors, emotion and psychology, family and social interpersonal relationship, and physiological characters (Concepcion et al., 2014). Good-quality sleep refers to an adult continuously sleep 6-8 hours per day with sleep latency less than $30 \mathrm{~min}$, sleep efficiency above $85 \%$, and sleep 
interruption time less than 30min to feel satisfaction with sleep and rest content after being awake (Alpert et al., 2015). Mehari, Weir, and Gillum (2014) mentioned that Buysse et al., in 1989, regarded quality, quantity, and indirect sleep related problems as the evaluation of sleep characteristics. Quality contained subjective sleep quality, sense of satisfaction with sleep, and sleep disturbance; quantity covered sleep duration, sleep latency, and sleep efficiency; and, indirect sleep related problems included use of sleeping medication and daytime dysfunction. In other words, sleep quality was individual sense of satisfaction with sleep, which was the comprehensive performance of subjective perception and objective calculation of sleep quantity.

Referring to Chen et al. (2016), sleep quality is extremely important for individual physiological health, wellbeing, and work efficiency that sleep disorder, sleep efficiency, and sleep duration are included in sleep quality in this study.

\section{Quality of Life}

Quality of life is a primary indicator of good life (Li et al., 2017). Individual health factors and satisfaction in life would influence physical and mental health, social economy, and family conditions. Individual perception of the cultural value in the life is related to personal goal, expectation, and standard, including physiology, psychology, society, individual, and environment (Antonishen, 2015) and satisfaction with individual perception of selfimportance in the life (Lan et al., 2014). Healthy quality of life referred to individual perception of health factors in life and satisfaction (Szymczynska et al., 2017). Caldwell et al. (2016) indicated that living was a key factor in modern people maintaining life and health, and quality of life should be extremely emphasized as positive development of lifestyles would promote quality of life. Peker (2016) revealed that quality of life related to health was emphasized in medical environment, as an individual might be affected physiologically, psychologically, and socially due to accidents, diseases, or treatment. Cheng (2015) therefore considered that good sleep quality was essential in individual health and life. Rodríguez-Sotelo et al. (2014) pointed out the definition of quality of life in World Health Organization (WHO) as people's perceived life under cultural value systems. Such perception was related to individual goal, expectation, standard, and concern. Grandner (2014) covered physiological health, psychological state, independency, social relationship, personal belief, and environment in such perception. Different experts proposed distinct definitions of quality of life. For instance, the damage and treatment effectiveness of disease were emphasized in medicine, and well-being and satisfaction with life were focused in nursing. Moreover, it could be divided into single dimension and multi-dimension, subjective or objective. Medical effectiveness analysis, clinical medical decision-making, health policy evaluation, and health risk management were applied to medicine (Zhuang et al., 2014).

Referring to Cheng (2015), two dimensions of health status and satisfaction with life are used for quality of life in this study.

\section{Research Hypothesis}

Bartels et al. (2015) pointed out various factors in sleep quality, e.g. social change, work stress, lifestyles, individual psychological and health status, living habits, environmental factors, types of diseases, and other physiological symptoms (Chiu et al., 2015). Rose et al. (2014) argued that medical education could improve lifestyles, individual psychology and living habits. Liang et al. (2016) pointed out the importance of health competency for sleep quality because it was necessary to understand the adjustment of pressure, the enhancement of individual psychology, and good living habits being able to prevent diseases, and health competency required medical education. In this case, good health competency required medical education (Lajnef et al., 2015). Based on above inference, the hypothesis is proposed in this study.

H1: Medical education shows significant correlation with sleep quality.

In the study on the correlation between after-disaster insomnia and quality of life, Lin (2016) revealed that people with after-disaster insomnia problems showed worse quality of life than those without insomnia problems. In the discussion of the effect of sleep diseases on the quality of life of elderly patients with hypertension, Cheng (2014) discovered that sleep disturbance would obviously affect patients' quality of life. According to above studies, people with problems in sleep quality would be influenced the quality of life (Alpert et al., 2015). Sofi et al. (2014) stated that bad sleep quality could result in students' bad performance on schoolwork and exercise, influence the emotion, and even cause psychological problems of melancholy later on. Sleep disorder is a common health problem for the public, in which insomnia problem is a disease seriously influencing quality of life in current industrial and commercial societies (Chen et al., 2016). Based on above inference, the hypothesis is proposed in this study.

H2: Sleep quality presents remarkable correlation with quality of life. 
Lin (2016) indicated that medical education allowed college students having further cognition of self-health concept to reflect on the physiological, psychological, and social perception of quality of healthy life and effectively enhance quality of life. Cheng (2015) mentioned that medical education could enhance health competency and further affect health, family, and even expenditure for health insurance (Li et al., 2017). Caldwell et al. (2016) pointed out the large effect of health competency on quality of life; especially, changing physical and mental health with lifestyles presented great influence on quality of life, and medical education would enhance useful concepts and strategies for people. It was understood that the enhancement of health competency with medical education was efficient self-care (Zou et al., 2017). Cheng (2015) proposed that medical education could effectively enhance health competency; ones with high health competency would better follow diet control, self-monitoring of blood glucose, and diet control, revealing the better autonomous management of health to further influence quality of life. According to above inference, the hypothesis is proposed in this study.

H3: Medical education reveals notable correlation with quality of life.

\section{RESEARCH METHOD DESIGN}

\section{Research Object}

Quasi-experiment is preceded in this study. Total 200 students in four classes of the University in Shanghai, as the research object, are proceeded the 16-week ( $3 \mathrm{hr}$ per week for total 48 hours) medical education. The retrieved data are analyzed with SPSS to test various hypotheses.

\section{Analysis}

Regression Analysis is applied to understand the relationship among students' medical education, sleep quality, and quality of life.

\section{Operational Definition and Measurement of Variable}

\section{Medical education}

Medical education is divided into two levels of health promotion and related behavior. The questions are scored with Likert 5-point scale, where 1 stands for extremely disagree and 5 for extremely agree. The overall reliability coefficients appear 0.86 and 0.82 for health promotion and related behavior, respectively.

\section{Sleep quality}

Sleep quality contains three levels of sleep disorder, sleep efficiency, and sleep duration. With Likert 5-point scale, 1 stands for extremely disagree and 5 for extremely agree. The overall reliability coefficients show $0.83,0.87$, and 0.84 for sleep disorder, sleep efficiency, and sleep duration, respectively.

\section{Quality of life}

Quality of life includes two levels of health status and satisfaction with life. With Likert 5-point scale, 1 stands for extremely disagree and 5 for extremely agree. The reliability coefficients reveal 0.83 and 0.88 for health status and satisfaction with life, respectively.

\section{ANALYSIS AND DISCUSSION}

\section{Regression Analysis of Medical Education and Sleep Quality}

Regression Analysis is utilized for testing the hypothesis and the theoretical structure in this study. The first regression tests the effect of medical education on sleep disorder. The results show positive effects of health promotion and related behavior on sleep disorder (Beta $=0.257, p=0.000$; Beta $=0.262, p=0.000$ ). The second regression tests the effect of medical education on sleep efficiency, where health promotion and related behavior appear positive and significant effects on sleep efficiency (Beta $=0.266, p=0.000 ;$ Beta $=0.282, p=0.000$ ). The third regression tests the effect of medical education on sleep duration, where health promotion and related behavior reveal positive and remarkable effects on sleep duration (Beta $=0.272, p=0.000 ;$ Beta $=0.278, p=0.000$, Table 1 . Accordingly, H1: medical education presents notable correlations with sleep quality is supported. 
Table 1. Regression Analysis of medical education and sleep quality

\begin{tabular}{|c|c|c|c|c|c|c|}
\hline \multirow{3}{*}{$\begin{array}{l}\text { dependent variable } \\
\text { independent variable }\end{array}$} & \multicolumn{6}{|c|}{ sleep quality } \\
\hline & \multicolumn{2}{|c|}{ sleep disorder } & \multicolumn{2}{|c|}{ sleep efficiency } & \multicolumn{2}{|c|}{ sleep duration } \\
\hline & Beta & $\mathrm{P}$ & Beta & $\mathrm{P}$ & Beta & $\mathrm{P}$ \\
\hline health promotion & 0.257 & 0.000 & 0.266 & 0.000 & 0.272 & 0.000 \\
\hline related behavior & 0.262 & 0.000 & 0.282 & 0.000 & 0.278 & 0.000 \\
\hline $\mathrm{F}$ & \multicolumn{2}{|c|}{17.213} & \multicolumn{2}{|c|}{19.611} & \multicolumn{2}{|c|}{22.458} \\
\hline $\mathrm{R}^{2}$ & \multicolumn{2}{|c|}{0.166} & \multicolumn{2}{|c|}{0.192} & \multicolumn{2}{|c|}{0.217} \\
\hline adjusted $R^{2}$ & \multicolumn{2}{|c|}{0.141} & \multicolumn{2}{|c|}{0.168} & \multicolumn{2}{|c|}{0.188} \\
\hline
\end{tabular}

Table 2. Regression Analysis of sleep duration and quality of life

\begin{tabular}{|c|c|c|c|c|}
\hline \multirow{3}{*}{$\begin{array}{l}\text { dependent variable } \\
\text { independent variable }\end{array}$} & \multicolumn{4}{|c|}{ quality of life } \\
\hline & \multicolumn{2}{|c|}{ health status } & \multicolumn{2}{|c|}{ satisfaction with life } \\
\hline & Beta & $\mathrm{P}$ & Beta & $\mathrm{P}$ \\
\hline sleep disorder & 0.296 & 0.000 & 0.287 & 0.000 \\
\hline sleep efficiency & 0.277 & 0.000 & 0.294 & 0.000 \\
\hline sleep duration & 0.283 & 0.000 & 0.302 & 0.000 \\
\hline $\mathrm{F}$ & \multicolumn{2}{|c|}{25.438} & \multicolumn{2}{|c|}{27.183} \\
\hline $\mathrm{R}^{2}$ & \multicolumn{2}{|c|}{0.244} & \multicolumn{2}{|c|}{0.271} \\
\hline adjusted $R^{2}$ & \multicolumn{2}{|c|}{0.212} & \multicolumn{2}{|c|}{0.243} \\
\hline
\end{tabular}

${ }^{*} \mathrm{p}<0.05{ }^{* *} \mathrm{p}<0.01$

Data source: Self-organized in this study

Table 3. Regression Analysis of medical education and quality of life

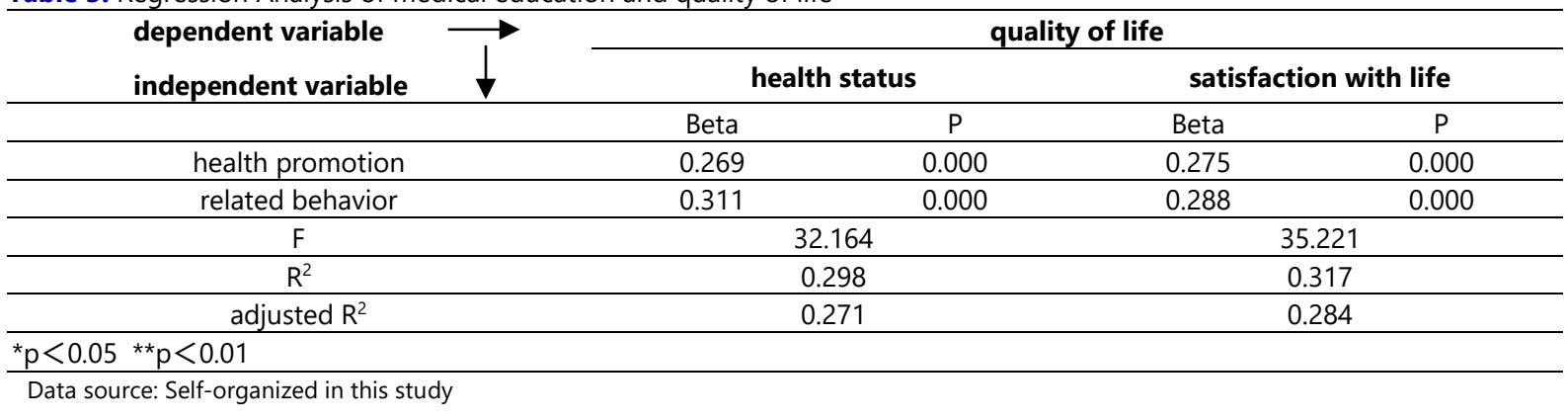

\section{Regression Analysis of Sleep Quality and Quality of Life}

Regression Analysis is applied to test the hypothesis and the theoretical structure in this study. The first regression tests the effect of sleep quality on health status, in which sleep disorder, sleep efficiency, and sleep duration appear positive effects on health status $(B e t a=0.296, p=0.000$; Beta $=0.277, p=0.000$; Beta $=0.283, p=$ $0.000)$. The second regression tests the effect of sleep quality on satisfaction with life, where sleep disorder, sleep efficiency, and sleep duration present positive and significant effects on satisfaction with life (Beta $=0.287, p=0.000$; Beta $=0.294, p=0.000$; Beta $=0.302, p=0.000$, Table 2. H2: sleep duration reveals remarkable correlation with quality of life is supported.

\section{Regression Analysis of Medical Education and Quality of Life}

Applying Regression Analysis to test the hypothesis and the theoretical structure in this study, the first regression tests the effect of medical education on health status. The results show positive effects of health promotion and related behavior on health status (Beta $=0.269, p=0.000$; Beta $=0.311, p=0.000$ ). The second regression tests the effect of medical education on satisfaction with life, and the results reveal positive and notable effects of health promotion and related behavior on satisfaction with life (Beta $=0.275, p=0.000$; Beta $=0.288, p=$ 0.000 , Table 3. As a result, H3: medical education shows remarkable correlations with quality of life is supported. 


\section{CONCLUSION}

The research results reveal that medical education allows students achieving the conditions of healthy lifestyles, enhancing the cultivation of regular living habits, and grasping learning opportunity to achieve health promotion and further promote quality of life. Medical education has broadened the source of health knowledge to make better health promotion. Besides, the intervention of medical education could reinforce students' self-health evaluation to more significantly change the sleep quality and quality of life. Medical education could have students perceive the good physical and mental conditions and affect the sleep quality, as a person with physical and emotional problems would not sleep well at night, and ones with bad health conditions would not have good sleep quality. The rapidly changing society could influence students' health behaviors and lifestyles. For this reason, future promotion of medical education should stress on courses conforming to student needs and time trend, expecting to enhance students' physical and mental health aiming at student needs.

\section{RECOMMENDATIONS}

By concluding the research results and findings, the following practical suggestions are proposed in this study.

1. The course and philosophy of medical education in teacher training schools are reinforced so that students pay attention to the cultivation of healthy living habits in the beginning of the school education, understanding the importance and function of medical education, and even being capable of applying it to the health behaviors in adult. It would assist in the cultivation of regular habits, presenting correct knowledge and skills, as well as enhancing learning and experiencing the establishment of health behaviors. When facing different environment in the future, necessary medical education materials could then be provided to help promote and establish health living behaviors at various ages.

2. Schools are suggested to encourage students participating in exercise through health promotion activity to cultivate regular exercise habits, enhance the atmosphere of students participating in exercise, and cultivate the habit of regular exercise so as to enhance personal health and create good sleep quality and quality of life. From the aspect of guidance, students are encouraged to engage in regular exercise, establish exclusive leisure sports clubs, thoroughly utilize the after-school time for exercise, arrange social activities among schools, and well utilize sport facilities in schools. Regular emotion related courses could be arranged to have students release emotional pressure through instructors' teaching and enhance well-being and reduce anxiety emotion by participating in the courses to further promote students' sleep quality and quality of life.

3. Medical education could be practiced with multi-culture and computer-assisted teaching is preceded through the Internet so that students could acquire health knowledge and resources from the network to achieve the self-learning ability and be responsible for self-health. Health promotion lifestyles, e.g. "diet health lifestyles", "physical exercise promotion", and "emotion management in health promotion" could be included in the annual health programs for regularly evaluate students' medical health behaviors to enhance students' health responsibility.

\section{REFERENCES}

Alpert, M. A., Nusair, M. B., Mukerji, R., Omran, J., Mehra, A., Ardhanari, S., Kumar, S. A., \& Terry, B. E. (2015). Effect of weight loss on ventricular repolarization in normotensive severely obese patients with and without heart failure. Am J Med Sci, 349(1), 17-23. https:/ / doi.org/10.1097/MAJ.0000000000000342

Antonishen, K. (2015). Exercise mode heterogeneity among reported studies of the qigong practice Baduanjin. Journal of Bodywork and Movement Therapies, 19(2), 278-283. https://doi.org/10.1016/j.jbmt.2014.05.013

Barons, M. J., Turner, S., Parsons, N., Griffiths, F., Bethell, H., Weich, S., \& Thorogood, M. (2015). Fitness predicts long-term survival after a cardiovascular event: A prospective cohort study. BMJ Open, 5(10), e007772. https:// doi.org/10.1136/bmjopen-2015-007772

Bartels, S. J., Pratt, S. I., Aschbrenner, K. A., Barre, L. K., Naslund, J. A., Wolfe, R., . . Bird, B. L. (2015). Pragmatic replication trial of health promotion coaching for obesity in serious mental illness and maintenance of outcomes. The American Journal of Psychiatry, 172(4), 344-352. https:/ / doi.org/10.1176/appi.ajp.2014.14030357

Bernert, R. A., Turvey, C. L., Conwell, Y., \& Joiner, T. E. Jr. (2014). Association of poor subjective sleep quality with risk for death by suicide during a 10-year period: a longitudinal, population-based study of late life. Psychiatry, 71(10), 1129-1137. https:/ / doi.org/10.1001/jamapsychiatry.2014.1126

Cakici, M., Dogan, A., Cetin, M., Suner, A., Caner, A., Polat, M., Kaya, H., Abus, S., \& Akturk, E. (2015). Negative effects of acute sleep deprivation on left ventricular functions and cardiac repolarization in healthy young adults. Pacing ClinElectrophysiol, 38(6), 713-722. https:/ / doi.org/10.1111/ pace.12534 
Caldwell, K. L., Bergman, S. M., Collier, S. R., Triplett, N. T., Quin, R., Bergquist, J., \& Pieper, C. F. (2016). Effects of tai chi chuan on anxiety and sleep quality in young adults: Lessons from a randomized controlled feasibility study. Nature and Science of Sleep, 8, 305-314. https:/ / doi.org/10.2147/NSS.S117392

Chen, M. D., Yeh, Y. C., Tsai, Y. J., Chang, Y. C., Yu, J. W., \& Hsu, C. H. (2016). Efficacy of Baduanjin exercise and feasibility of mobile text reminders on follow-up participation in people with severe mental illness: An exploratory study. Journal of Psychiatric Practice, 22(3), 241-249. https:/ / doi.org/10.1097/PRA.0000000000000158

Cheng, F. K. (2015). Does movement-based taiji contribute to mental health? A comprehensive review. Journal of Nature and Science, 1(5), e94. Retrieved from http:/ / www.jnsci.org/index.php?journal=nsci\&page=article\&op=view\&path $\% 5 B \% 5 D=94 \&$ path $\% 95 \mathrm{~B} \% 9$ $5 \mathrm{D}=424$

Cheng, Y. (2014) Working hours, sleep duration and the risk of acute coronary heart disease: A case-control study of middle-aged men in Taiwan. International journal of cardiology, 171(3), 419-422. https:// doi.org/10.1016/j.ijcard.2013.12.035

Chiu, L. Y. L., Stewart, K., Woo, C., Yatham, L. N., \& Lam, R. W. (2015). The relationship between burnout and depressive symptoms in patients with depressive disorders. Journal of Affective Disorders, 172(0), 361-366. https:/ / doi.org/10.1016/j.jad.2014.10.029

Concepcion, T., Barbosa, C., Vélez, J. C., Pepper, M., Andrade, A., Gelaye, B., \& Williams, M. A. (2014). Daytime Sleepiness, Poor Sleep Quality, Eveningness Chronotype, and Common Mental Disorders among Chilean College Students. Journal of American College Health, 62(7), 441-448. https:/ / doi.org/10.1080/07448481.2014.917652

de Arriba Pérez, F., Santos Gago, J. M., \& Caeiro Rodríguez, M. (2016). Analytics of biometric data from wearable devices to support teaching and learning activities. Journal of Information Systems Engineering \& Management, 1(1), 41-54. https:/ / doi.org/10.20897/lectito.201608

Grandner, M. A. (2014). Addressing sleep disturbances: An opportunity to prevent cardiometabolic disease? International Review of Psychiatry, 26(2), 155-176. https:/ / doi.org/10.3109/09540261.2014.911148

Kayaba, M., Ihara, T., Kusaka, H., Iizuka, S., Miyamoto, K., \& Honda, Y. (2014). Association between sleep and residential environments in the summertime in Japan. Sleep medicine, 15, 556-564. https:// doi.org/10.1016/j.sleep.2013.11.784

Lajnef, T., Chaibi, S., Ruby, P., Aguera, P.-E., Eichenlaub, J.-B., Samet, M., . . Jerbi, K. (2015). Learning machines and sleeping brains: automatic sleep stage classification using decision-tree multi-class support vector machines. Journal of neuroscience methods, 250, 94-105. https:/ / doi.org/10.1016/j.jneumeth.2015.01.022

Lan, L., et al. (2014), Experimental study on thermal comfort of sleeping people at different air temperatures. Building and Environment, 73, 24-31. https://doi.org/10.1016/j.buildenv.2013.11.024

Li, X., Cui, L., Tao, S., Chen, J., Zhang, X., \& Zhang, G.-Q. (2017). HyCLASSS: A Hybrid Classifier for Automatic Sleep Stage Scoring. IEEE Journal of Biomedical and Health Informatics.

Liang, S.-F., Kuo, C.-E., Shaw, F.-Z., Chen, Y.-H., Hsu, C.-H., \& Chen, J.-Y. (2016). Combination of expert knowledge and a genetic fuzzy inference system for automatic sleep staging. IEEE Transactions on Biomedical Engineering, 63(10), 2108-2118. https:/ / doi.org/10.1109/TBME.2015.2510365

Lin, Y.-S. (2016). A Rule-based Automatic Sleep Scoring System for the Healthy Individuals and Insomnia Subjects (Master Thesis), National Cheng Kung University, Taiwan.

Mehari, A., Weir, N. A., \& Gillum, R. F. (2014). Gender and the association of smoking with sleep quantity and quality in American adults. Women Health, 54(1), 1-14. https:/ / doi.org/10.1080/03630242.2013.858097

Moon, J. H., Kong, M. H., Oh, Y. H., Kim, H. J. (2018). Effect of sleep duration on muscle mass in Korean non-elderly adults. Electronic Journal of General Medicine, 15(2), em03. https:/ / doi.org/10.29333/ ejgm/81763

Peker, M. (2016). A new approach for automatic sleep scoring: Combining Taguchi based complex-valued neural network and complex wavelet transform. Computer methods and programs in biomedicine, 129, 203-216. https:/ / doi.org/10.1016/j.cmpb.2016.01.001

Rodríguez-Sotelo, J. L., Osorio-Forero, A., Jiménez-Rodríguez, A., Cuesta-Frau, D., Cirugeda-Roldán, E., \& Peluffo, D. (2014). Automatic sleep stages classification using eeg entropy features and unsupervised pattern analysis techniques. Entropy, 16(12), 6573-6589. https:/ / doi.org/10.3390/e16126573

Rose, D., Gelaye, B., Sanchez, S., Castaneda, B., Sanchez, E., Yanez, N. D., \& Williams, M. A. (2014). Morningness/eveningnesschronotype, poor sleep quality, and daytime sleepiness in relation to common mental disorders among Peruvian college students. Psychol Health Med, 1-8. 
Sofi, F., Cesari, F., Casini, A., Macchi, C., Abbate, R., \& Gensini, G. F. (2014). Insomnia and risk of cardiovascular disease: a meta-analysis. Eur J Prev Cardio, 21, 57-64. https:/ / doi.org/10.1177/2047487312460020

Szymczynska, P., Walsh, S., Greenberg, L., \& Priebe, S. (2017). Attrition in trials evaluating complex interventions for schizophrenia: Systematic review and meta-analysis. Journal of Psychiatric Research, 90, 67-77. https://doi.org/10.1016/j.jpsychires.2017.02.009

Wysocki, J., Balcerzak, J., Prus, M., Niemczyk, K., Lachowska, M. (2016). Sleep Quality and Atherogenic Risk in Sleep Apnea Patients. European Journal of General Medicine, 13(1), 28-36. https://doi.org/10.15197/ejgm.01476

Zhuang, J., Huang, L., Wu, Y., \& Zhang, Y. (2014). The effectiveness of a combined exercise intervention on physical fitness factors related to falls in community-dwelling older adults. Clinical Interventions in Aging, 9, 131-140. https://doi.org/10.2147/CIA.S56682

Zou, L., Sasaki, J. E., Wang, H., Xiao, Z., Fang, Q., \& Zhang, M. (2017). A systematic review and meta-analysis of Baduanjin qigong for health benefits: Randomized controlled trials. Evidence-Based Complementary and Alternative Medicine. https:/ / doi.org/10.1155/2017/4548706

\section{http://www.ejmste.com}

